\title{
mHealth for Tuberculosis Treatment Adherence: A Framework to Guide Ethical Planning, Implementation, and Evaluation
}

\author{
Michael J DiStefano, ${ }^{a}$ Harald Schmidt ${ }^{b}$
}

Promising mHealth approaches for TB treatment adherence include:

- Video observation

- Patient- or device-facilitated indirect monitoring

- Direct monitoring through embedded sensors or metabolite testing

To mitigate ethical concerns, our framework considers accuracy of monitoring technologies, stigmatization and intrusiveness of the technologies, use of incentives, and the balance of individual and public good.

\section{INTRODUCTION}

\begin{abstract}
A dherence to tuberculosis (TB) treatment is important for promoting individual and public health. Poor adherence results in more individual suffering and death as well as more costly treatment as treatment regimens lengthen and drug resistance develops. As resource allocation pressures intensify under the Sustainable Development Goals and the global push for universal health coverage, ${ }^{1}$ exploring novel ways of improving adherence is timely and important.

Mobile health (mHealth) holds considerable promise to improve quality and efficiency in health care. ${ }^{2}$ Yet its potential for TB adherence remains largely unexplored, ${ }^{3,4}$ and there is a lack of people-centered mHealth approaches responsive to the complexity of real life. ${ }^{5}$ Also lacking are ethical evaluations of mHealth interventions, ${ }^{6,7}$ particularly those considering the nuances of disease- and goal-specific interventions. Perceived and real acceptability cannot be taken for granted. The planning, implementation, and evaluation of mHealth interventions for TB treatment adherence must be guided by values as much as by technical innovation.
\end{abstract}

\footnotetext{
a University of Pennsylvania, Department of Medical Ethics and Health Policy, Philadelphia, PA, USA.

b University of Pennsylvania, Department of Medical Ethics and Health Policy, Center for Health Incentives and Behavioral Economics, Philadelphia, PA, USA.

Correspondence to Michael J DiStefano (mjad88@gmail.com).
}

In this article, we describe salient mHealth approaches to monitor and enhance TB treatment adherence, establish a framework for consideration of the central ethical issues, particularly when mHealth is paired with incentives, and outline a model to help guide the ethical planning, implementation, and evaluation of future mHealth interventions for adherence. In doing so, we highlight areas of ethical concern as well as opportunities for ethical improvement over direct observation of therapy (DOT), the global standard for monitoring TB treatment adherence.

\section{TUBERCULOSIS AND THE IMPORTANCE OF ADHERENCE}

In 2014, 9.6 million people became ill with $\mathrm{TB}$ and 1.5 million died, ranking TB alongside HIV as a leading cause of death worldwide. ${ }^{8}$ More than $95 \%$ of TB deaths occur in low- and middle-income countries (LMICs). ${ }^{9}$

According to the World Health Organization (WHO), the optimal TB treatment plan consists of an initial treatment phase requiring daily ingestion of 4 first-line anti-TB drugs for 2 months, followed by a 4-month continuation phase during which 2 daily drugs are necessary. Regimens of ingesting drugs thrice weekly in both the initial and continuation phase are also possible. $^{10} \mathrm{~TB}$ susceptible to first-line drugs is called drug-susceptible TB (DS-TB). Two forms of drugresistant TB (DR-TB) are widely recognized: multidrugresistant TB and extensively drug-resistant TB. Treating 


\section{mHealth interventions for TB treatment adherence must be guided by ethical values as much as by technical innovation.}

Proper TB
treatment rests in
part on proper
patient
adherence, so
monitoring and
enhancing
adherence is
critical.

New TB treatment adherence monitoring techniques should be compared with DOT in terms of ethical acceptability.

Barriers to TB
treatment
adherence can be
many, relating to
structural, patient,
social, and health
care service
factors.
even the less resistant forms of DR-TB can take up to 2 years and may also require daily medication.

Proper treatment of all forms of TB is critical to reducing individual morbidity and mortality and to interrupting transmission among family and community members. Proper treatment also limits the development and spread of DR-TB. Treatment for DR-TB is more expensive, less effective, and has more serious side effects. ${ }^{11}$ The impact of poor treatment on morbidity, mortality, and disease transmission is exacerbated by poverty, weak health systems, and low levels of health literacy found in many LMICs. Because proper treatment rests in part on proper adherence, monitoring and enhancing adherence is important to safeguarding both individual and public health.

Ensuring adherence is therefore a key component of WHO's post-2015 global TB strategythe "End TB Strategy." Pillar I of this strategy calls for "supportive treatment supervision ... [to help] patients to take their medication regularly and to complete treatment, thus facilitating their cure and preventing the development of drug resistance." 12 The strategy indicates supervision should be "carried out in a context-specific and patient-sensitive manner" and acknowledges the many barriers to adherence, including "educational, emotional, and material needs," "stigmatization and discrimination," and health-system factors ${ }^{12}$ Given these diverse barriers, supportive treatment supervision will be necessarily complex, spanning interventions to train treatment partners, provide greater social protection, disseminate and exchange necessary information and experiences across potentially long distances, and using incentives.

Where supportive treatment supervision includes monitoring of adherence, DOT (i.e., when a health worker directly witnesses the swallowing of anti-TB drugs in a clinical, community, work, or personal setting) has long been recommended by WHO and is the global standard of care. New adherence monitoring techniques should therefore be compared with DOT in terms of ethical acceptability.

\section{Barriers to Adherence}

While DOT has seen great success in specific contexts, ${ }^{13}$ its limitations can be understood against the barriers of non-adherence recognized in WHO's End TB Strategy. Munro et al. elaborated on these barriers by identifying and describing
4 categories of adherence barriers related to structural, patient, social, and health care service factors. ${ }^{14}$ The influence and interplay of these 4 factors vary. Addressing non-adherence to TB treatment therefore requires awareness of context and targeting all relevant factors.

\section{Structural Factors}

Structural factors are obstacles, such as poverty and gender, over which patients have very little control and which can complicate adherence even when patients are strongly motivated. Poverty, especially when linked to the factors discussed below, can impact adherence. For example, where treatment costs are not covered, poor patients or those supporting others, may feel they must choose between work and health. In LMICs, the mean total cost of TB (i.e., direct medical and non-medical costs and lost income due to sickness) is $39 \%$ of annual reported household income, and $148 \%$ at its highest. ${ }^{15}$ Gender-related factors may also impact adherence. TB-related stigma can lead to greater concealment and denial of disease among women than men, and gender roles within traditional or poor families that translate to women having less leisure time and status may result in greater difficulties for women to pursue treatment. ${ }^{16}$

\section{Patient Factors}

Variations in patient motivation and willingness can also impact adherence and may be affected by forgetfulness, a lack of understanding regarding the importance of TB treatment, general interpretations of illness such as the belief that one is sick only if symptomatic, alcohol or drug use, or a perceived loss of agency and aversion to elements of control and surveillance associated with DOT. Furthermore, side effects of TB drugs, which include fever, fatigue, weakness, nausea, vomiting, hepatitis, or death, ${ }^{17}$ can affect patient motivation due to unpleasantness or substantial interference with a patient's ability to work. This is especially true as the side effects grow more diverse and severe during DR-TB treatment to include psychiatric disorders, hearing loss, and epileptic seizures. ${ }^{18}$

\section{Social Context}

Strong social support within a patient's family, community, or health care context can help counteract structural and personal barriers to 
adherence by influencing motivation or knowledge and beliefs about TB. However, lack of support or knowledge about TB and its treatment in a patient's family, community, or health care context, as well as real or perceived stigmatization of the sick, can hinder adherence.

\section{Health Care Service Factors}

Inadequate drug stocks, long waiting times, inconvenient service hours, and difficulties accessing health facilities reveal the opportunity costs associated with attending health facilities, such as neglecting household responsibilities (e.g., caring for one's children) and losing work and income. All these factors can therefore thwart adherence to TB treatment. For example, a study in Ethiopia found that the average patient traveled approximately 70 hours to a DOT health facility. Following the initial treatment phase, patients traveled only once per month to a DOT health facility to collect drugs. Distance rendered regular observation of drug ingestion impractical (either on a daily or alternating daily basis) and may have contributed to treatment success rates that fell below WHO targets. ${ }^{19}$

\section{THE PROMISE OF MHEALTH FOR TB TREATMENT ADHERENCE}

While a multitude of barriers to TB treatment adherence needs to be considered, mHealth interventions can potentially address several central adherence challenges. First, the number of mobile cellular subscriptions per 100 people in LMICs is 87 and growing ${ }^{20}$ : mHealth can potentially obviate DOT-related travel and improve adherence in remote areas. Second, mHealth may improve health system efficiency in regions where resources and trained medical professionals are very scarce. For instance, in South Africa, an intervention that relies on mobile phones and SMS (short message service) has enabled nurses to track 50 to $60 \mathrm{~TB}$ patients instead of only 10 , thus making time to focus on otherwise neglected aspects of their work. ${ }^{21}$

Additionally, mHealth can address important patient factors in non-adherence by facilitating novel and sophisticated ways of providing financial and non-financial incentives. For example, a study of warfarin adherence used pill compartments that wirelessly entered patients into a daily lottery when opened according to the prescribed treatment plan, ${ }^{22}$ therefore eliminating the need for human observation and recordkeeping. Mobile platforms can also help overcome some logistical challenges of incentive delivery. Examples from Kenya, ${ }^{23}$ Malawi, ${ }^{24}$ and Zambia ${ }^{24}$ demonstrate the feasibility of efficient electronic transfer schemes that eliminate the need for travel to a bank or remote patient areas, potentially expanding the reach of incentive programs, lowering the costs of incentive delivery, and rendering the process more sustainable.

Finally, empirical research supports mHealth's promise for improving adherence. A recent study, the first to conduct a large and rigorous trial in this area, found that electronic reminders from medication monitors improved TB treatment adherence. $^{25}$ Various smaller, proof-of-concept studies have established the potential benefit of using other forms of mHealth for TB adherence. ${ }^{4}$

\section{AN ETHICAL FRAMEWORK}

We conducted a comprehensive search of PubMed and Google Scholar on March 15, 2016, for mHealth interventions focused on TB adherence using the following 2 search strings:

- “adherence AND (eHealth OR mHealth OR 'electronic health' OR 'mobile health' OR e-health OR m-health)"

- “adherence[Title/Abstract]) AND "systematic review"[Title/Abstract]) AND (eHealth OR mHealth OR 'electronic health' OR 'mobile health' OR e-health OR m-health)”

Adapting and adding to previously identified types of mHealth for TB adherence, ${ }^{26}$ we constructed the following 5 intervention categories (Table 1):

1. Video observation of therapy (VOT): patients use smartphones to record videos of themselves taking each medication dose, allowing health care workers to view the videos either synchronously or asynchronously; facial recognition and motion-detecting software can even replace the need for human observation

2. Indirect monitoring technology, patientfacilitated (IP): after ingesting their medication, patients place a free call or send an SMS to a central server

3. Indirect monitoring technology, devicefacilitated (ID): after the patient removes the cap of the medication bottle, a message is wirelessly transmitted to a central server

\author{
mHealth can \\ facilitate novel \\ ways of providing \\ financial and \\ non-financial \\ incentives to \\ encourage \\ TB treatment \\ adherence.
}


TABLE 1. Types of mHealth Interventions for TB Treatment Adherence Compared With the Global Standard of Direct Observation of Therapy

\begin{tabular}{lll}
\hline Intervention Category & \multicolumn{1}{c}{ Examples } & \multicolumn{1}{c}{ Description } \\
\hline $\begin{array}{l}\text { Direct observation of therapy } \\
\text { (DOT) - Global standard }\end{array}$ & WHO DOTS & A DOT worker directly observes and records patient swallowing medication. \\
$\begin{array}{l}\text { Video observation of therapy } \\
\text { (VOT) }\end{array}$ & $\begin{array}{l}\text { VDOT System } \\
\text { Automated } \\
\text { DOT }^{29}\end{array}$ & $\begin{array}{l}\text { Patients use smartphones to record videos of themselves taking each dose of } \\
\text { medication. Observation by a health official can be either synchronous } \\
(\text { "video conferencing") or asynchronous ("store-and-forward"). } \\
\text { systems, such as the Automated DOT software, replace human observation } \\
\text { with facial recognition and motion-detecting software. }\end{array}$
\end{tabular}

Indirect monitoring technology

Patient-facilitated (IP)

SIMmed $^{21}$ 99 dots $^{30}$

Device-facilitated (ID)

SIMpill ${ }^{21}$ MEMSCap 31

GlowCap ${ }^{32}$

Wisepill ${ }^{33}$

Patients place a free call or send an SMS to a central server after ingesting medication.

Medication bottles containing a SIM card or other sensor wirelessly transmit message to a central server following medication cap removal by a patient.

Direct monitoring technology

Embedded sensors (DE) ID- $\quad$-cap ${ }^{34}$

Proteus $^{35}$

Metabolite testing (DM)

Adhere. $10^{36}$

A wearable hub that attaches to the patient's wrist, arm, hip, or abdomen detects when the patient ingests medication or a pill capsule, equipped with an ingestible sensor, and wirelessly transmits the data to a central server.

Metabolite testing (DM) Adhere.1O

Patients receive low-cost, encrypted chromatography test strips for home use, which reveal codes when correct drug metabolites are detected in the patient's urine. The patient sends an SMS with the code to a central server.

Abbreviations: DOTS, directly observed treatment, short-course; SIM, subscriber identification module; SMS, short message service; TB, tuberculosis; $\mathrm{WHO}$, World Health Organization.

\section{Any mHealth \\ adherence intervention can comprise (1) a monitoring technology and (2) features that use monitoring data to enhance adherence.}

4. Direct monitoring technology, embedded sensors (DE): when the patient ingests the medication, which is equipped with an ingestible sensor, a wearable hub attached to the patient's body wirelessly transmits the data to a central server

5. Direct monitoring technology, metabolite testing (DM): patients use low-cost, encrypted chromatography urine test strips, which detect drug metabolites in the patients' urine revealing a code; the patients then send an SMS with the code to a central sever

In our analysis, we considered the possibility that any mHealth intervention for adherence can comprise, first, a monitoring technology and, second, features that use monitoring data to enhance adherence, such as personal reminders or incentives. We discuss the potential of the 5 categories of mHealth interventions to ethically monitor and enhance TB treatment adherence in line with WHO's “supportive treatment supervision" guidelines, and in comparison with DOTthe global standard of care for adherence monitoring. Building on prior work that analyzed the ethics of policies to promote individual responsibility for health, ${ }^{37}$ we developed an analytical framework for this comparison that comprises 4 ethically relevant elements:

\section{Accuracy of monitoring technologies}

2. Stigmatization and intrusiveness of monitoring technologies

3. The use of incentives

4. The balance of individual and public good

In discussing strengths and weaknesses of each mHealth intervention category, we identify areas of ethical concern as well as opportunities for ethical improvement over DOT. Finally, we outline a model using the 4 ethical elements to 
help guide the ethical planning, implementation, and evaluation of future mHealth interventions for TB adherence (Table 2). This recommended model will always require adaptation to suit specific contexts-for example, the relative prevalence of DS-TB versus DR-TB in resourcelimited settings and the different challenges presented by varying levels of government oversight-but hopefully provides useful baseline orientation.

\section{Accuracy of Monitoring Technologies}

Health officials must have accurate knowledge of non-adherent patients in order to provide individual support and protect public health. Monitoring technologies that accurately capture adherence data in a cost-effective and minimally burdensome way are therefore of considerable relevance to public health and the health of individuals.

Each monitoring technology presents distinct technical challenges, but here we are concerned with the potential for accuracy assuming optimal technical functioning. DOT is highly accurate in monitoring adherence as it requires direct observation. However, patients could feign drug ingestion, ${ }^{39}$ or DOT workers may generate false reports, thus overreporting adherence, or simply not provide treatment according to DOT guidelines. ${ }^{40}$ VOT is subject to similar accuracy concerns, ${ }^{41}$ although employing facial recognition software can avoid issues associated with human observers. IP/ID faces greater accuracy challenges than DOT or VOT. IP may require placing a free call to a central server after taking medication. ID may use medication bottles that automatically transmit messages to a server following cap removal. It is relatively easy for patients to falsely report adherence by placing calls or removing pill caps without ingesting medication. In terms of accuracy, DE and DM are potentially superior to DOT, VOT, and IP/ID by requiring actual ingestion of the drugs rather than health worker or patient reports.

\section{Stigmatization and Intrusiveness of Monitoring Technologies}

DOT is potentially stigmatizing by sometimes requiring health personnel to be present in patients' workplaces or communities, which may distinguish patients and result in unwanted public disclosure of disease status. ${ }^{42}$ Because stigmatization can deter patients with TB from seeking treatment ${ }^{14}$ and has other serious socioeconomic implications, ${ }^{42}$ monitoring technologies that increase stigmatization are harmful to these individuals and counter-productive from a public health perspective. Monitoring technologies that focus unwanted attention on patients should therefore be avoided.

DE that employs visibly worn wireless hubs risks stigmatizing patients. In most current forms, DE uses ingestible sensors embedded in either pills or standard pill capsules. A wearable hub that attaches to the wrist, arm, hip, or abdomen detects when capsules have been swallowed and transmits adherence data wirelessly to a central server. VOT and IP/ID are less stigmatizing by not requiring patients to publicly meet with health personnel or wear a potentially visible hub. Similarly, urinalysis-based DM would be less stigmatizing if employed in regions where people have privacy when relieving themselves.

Patients have reported that DOT feels like "doing time" and that it is "awkward" to be observed while taking treatment. ${ }^{14}$ DOT can be perceived as dehumanizing ${ }^{43}$ and may therefore contribute to self-stigma, characterized by low self-esteem and self-efficacy. ${ }^{44}$ Alternatively, patients have reported that VOT allowed them to retain a sense of control over their care, ${ }^{28}$ thus promoting autonomy, and that VOT was less intrusive than DOT given that videophone conferences last only a few minutes and can be scheduled with greater flexibility. ${ }^{41}$ DE that employs wearable monitoring technologies may extend perceptions of intrusive surveillance, even if worn invisibly beneath clothing. ${ }^{45}$ (Although there is debate in the electronic health field over the precise meanings of "intrusiveness" and "obtrusiveness," 46 we use the former for simplicity's sake.) Additionally, wearable technologies could be equipped to enable location surveillance of patients by authorities in a way not possible with IP/ID, DM, and VOT, which are nonwearable, and may have detrimental effects on these grounds. Governments may use adherence data to identify problematic or expensive patients and initiate more active engagement in potentially unwelcome forms, such as compulsory detention. ${ }^{47}$ To varying extents, these possibilities show that tensions between particular monitoring technologies and respecting individual autonomy are possible.

VOT, IP/ID, and DM respect individual autonomy better than DOT and DE by relying on less intrusive involvement in adherence monitoring.

\section{Monitoring technologies that focus unwanted attention on patients should be avoided.}

Direct monitoring technology through embedded sensors or metabolite testing, which require actual ingestion of drugs, are potentially more accurate than DOT and other technologies that depend on health worker or patient reports.

\section{Video observation, indirect monitoring, and direct monitoring through metabolite testing respect patient autonomy better than DOT.}


TABLE 2. Framework for the Ethical Evaluation of DOT and mHealth Interventions for TB Treatment Adherence, by Deceasing Accuracy of Adherence Detection

\begin{tabular}{|c|c|c|c|c|c|}
\hline \multicolumn{2}{|c|}{ Intervention } & \multicolumn{4}{|c|}{ Criteria for Ethical Evaluation } \\
\hline $\begin{array}{l}\text { (1) Monitoring } \\
\text { Technology }\end{array}$ & $\begin{array}{l}\text { (2) Feature(s) to } \\
\text { Enhance Patient } \\
\text { Adherence }\end{array}$ & (1) Accuracy & $\begin{array}{l}\text { (2) Stigmatization and } \\
\text { Intrusiveness }\end{array}$ & $\begin{array}{l}\text { (3) The Use of } \\
\text { Incentives }\end{array}$ & $\begin{array}{l}\text { (4) Balance of Individual } \\
\text { and Public Good }\end{array}$ \\
\hline $\begin{array}{l}\text { Direct monitoring } \\
\text { technology (metabolite } \\
\text { testing) (DM) }\end{array}$ & \multirow{5}{*}{$\begin{array}{l}\text { Follow-up by health } \\
\text { care workers when } \\
\text { non-adherent } \\
\text { SMS reminders to } \\
\text { take medication } \\
\text { throughout } \\
\text { treatment } \\
\text { Reward incentives } \\
\text { (e.g., in-kind } \\
\text { goods, or } \\
\text { reductions in } \\
\text { insurance } \\
\text { contributions) } \\
\text { conditional on } \\
\text { good adherence } \\
\text { Penalty incentives } \\
\text { (e.g., insurance } \\
\text { surcharges) when } \\
\text { non-adherent }\end{array}$} & $\begin{array}{l}\text { Most accurate: } \\
\text { medication ingestion } \\
\text { and metabolization is } \\
\text { necessary for adherence } \\
\text { detection }\end{array}$ & $\begin{array}{l}\text { Least risk: urinalysis can be } \\
\text { used with greater privacy } \\
\text { and does not enable } \\
\text { surveillance; respect for } \\
\text { patient agency and } \\
\text { autonomy }\end{array}$ & \multirow{5}{*}{$\begin{array}{l}\text { General risk of coercion } \\
\text { with penalty incentives } \\
\text { Incentive size: incentives } \\
\text { that are too small may fail } \\
\text { to address all relevant } \\
\text { adherence barriers; } \\
\text { incentives that are too large } \\
\text { may have greater risk of } \\
\text { coercion } \\
\text { Incentive type: guaranteed } \\
\text { rewards may have greater } \\
\text { risk of coercion than } \\
\text { lotteries and may be more } \\
\text { likely to "crowd-out" } \\
\text { intrinsic patient motivation } \\
\text { Incentive frequency: less } \\
\text { frequent incentives may } \\
\text { increase patients' } \\
\text { susceptibility to present- } \\
\text { biased preferences }\end{array}$} & \multirow{5}{*}{$\begin{array}{l}\text { General risk of violating } \\
\text { patient freedom and } \\
\text { privacy when using } \\
\text { individual adherence data } \\
\text { to develop a picture of } \\
\text { population-level adherence } \\
\text { or to assist in contact } \\
\text { tracing }\end{array}$} \\
\hline $\begin{array}{l}\text { Direct monitoring } \\
\text { technology (embedded } \\
\text { sensors) (DE) }\end{array}$ & & $\begin{array}{l}\text { Most accurate: } \\
\text { medication ingestion is } \\
\text { necessary for adherence } \\
\text { detection, but patients } \\
\text { could induce vomiting }\end{array}$ & $\begin{array}{l}\text { Most risk: if visible, } \\
\text { wearable hub is potentially } \\
\text { stigmatizing; even if } \\
\text { invisible, may enable } \\
\text { location surveillance and } \\
\text { identification of "problem" } \\
\text { patients; restricted patient } \\
\text { agency and autonomy }\end{array}$ & & \\
\hline $\begin{array}{l}\text { Video observation of } \\
\text { therapy (VOT) }\end{array}$ & & \multirow{2}{*}{$\begin{array}{l}\text { Fairly accurate: } \\
\text { swallowing is observed, } \\
\text { but patients can feign } \\
\text { ingestion or, where a } \\
\text { human observer is } \\
\text { required, collude to } \\
\text { create false report }\end{array}$} & $\begin{array}{l}\text { Least risk: can be used with } \\
\text { greater privacy and does } \\
\text { not enable surveillance; } \\
\text { respect for patient agency } \\
\text { and autonomy }\end{array}$ & & \\
\hline $\begin{array}{l}\text { Direct observation of } \\
\text { therapy (DOT) }\end{array}$ & & & $\begin{array}{l}\text { Most risk: association of } \\
\text { patient with health care } \\
\text { worker can be stigmatizing; } \\
\text { restricted patient agency } \\
\text { and autonomy }\end{array}$ & & \\
\hline $\begin{array}{l}\text { Indirect monitoring } \\
\text { technology (patient- } \\
\text { and device-facilitated) } \\
\text { (IP and ID) }\end{array}$ & & $\begin{array}{l}\text { Least accurate: } \\
\text { swallowing not } \\
\text { observed; patient can } \\
\text { place false call or } \\
\text { remove cap without } \\
\text { taking medication }\end{array}$ & $\begin{array}{l}\text { Least risk: can be used with } \\
\text { greater privacy and does } \\
\text { not enable surveillance; } \\
\text { respect for patient agency } \\
\text { and autonomy }\end{array}$ & & \\
\hline $\begin{array}{l}\text { Recommended } \\
\text { intervention }\end{array}$ & $\begin{array}{l}\text { Follow-up by health } \\
\text { care workers when } \\
\text { non-adherent } \\
\text { SMS reminders to } \\
\text { take medication } \\
\text { throughout } \\
\text { treatment } \\
\text { Reward incentives } \\
\text { (e.g., in-kind } \\
\text { goods, or } \\
\text { reductions in } \\
\text { insurance } \\
\text { contributions) } \\
\text { conditional on } \\
\text { good adherence }\end{array}$ & $\begin{array}{l}\text { Maximize accuracy by } \\
\text { minimizing opportunity } \\
\text { for patient deception } \\
\text { and adherence } \\
\text { overreporting }\end{array}$ & $\begin{array}{l}\text { Minimize stigmatization } \\
\text { and intrusiveness to } \\
\text { preserve patient agency } \\
\text { and promote autonomy }\end{array}$ & $\begin{array}{l}\text { Use reward incentives, but } \\
\text { minimize risk of coercion } \\
\text { by using 2-way SMS or } \\
\text { video conferencing } \\
\text { between patients and } \\
\text { providers } \\
\text { Reward value should be } \\
\text { carefully tailored to local } \\
\text { social and economic } \\
\text { context (smaller value to } \\
\text { address patient factor } \\
\text { barriers; larger value to } \\
\text { address non-patient factor } \\
\text { barriers) } \\
\text { Daily/weekly lottery }\end{array}$ & $\begin{array}{l}\text { Develop population-level } \\
\text { picture of adherence to } \\
\text { more efficiently use } \\
\text { resources, learn about best } \\
\text { practices and regions } \\
\text { where improvement is } \\
\text { needed, and ensure timely } \\
\text { drug restocking } \\
\text { Strive for anonymity, thus } \\
\text { promoting public good } \\
\text { while minimizing restriction } \\
\text { of individual freedom and } \\
\text { privacy }\end{array}$ \\
\hline
\end{tabular}


Such technologies are potentially agency-promoting, while the others may be experienced as more controlling technologies that limit autonomy.

\section{The Use of Incentives}

Incentives may be paired with mHealth monitoring technologies to enhance adherence. There is demonstrated interest in understanding whether incentives can effectively enhance TB treatment adherence within a non-mHealth context, ${ }^{48}$ as well as whether incentives paired specifically with mHealth monitoring can effectively enhance adherence within non-TB disease contexts. ${ }^{22}$ Therefore, it is possible in principle to envision the combination of incentives and mHealth monitoring to enhance TB treatment adherence, especially given that mHealth can facilitate and enable the administration of incentives in various ways.

It might seem odd to offer follow-up, reminders, or incentives assuming that-absent external barriers, particularly structural, social, or health care service factors-patients should have a clear self-interest in taking their medication. Yet even when external barriers are not an issue, adherence rates are not ideal. For example, one study identified a $22 \%$ rate of incorrect warfarin doses to prevent blood clotting even when cost and distance were not significant adherence barriers. ${ }^{22}$ Behavioral economists have systematically studied the reasons for such behavior. Decision errors include powerful cognitive mechanisms such as present-biased preferences, in which short-term benefits are given disproportionate weight relative to long-term benefits. ${ }^{49}$ In the case of TB adherence, this phenomenon may lead patients to prioritize immediate relief from medication side effects (by not taking the medication) over the future possibility of cure, even when cure is desired. Even absent side effects, the effort required to regularly take medication can overshadow long-term gains. The challenging life circumstances often found in LMICs only exacerbate these difficulties. Incentives that offer a tangible short-term benefit can counteract these dynamics and help patients overcome such biases. $^{50}$

For these reasons, interventions to enhance TB treatment adherence, including both DOT and mHealth approaches, may employ incentives alongside adherence monitoring, although many, including DOT, often do not do so because administering incentives can have unintended effects or be logistically challenging. ${ }^{51}$ Insofar as these challenges can be met, however, we discuss here the risk of coercion associated with using incentives as well as the size, type, and frequency of the incentive.

\section{The Risk of Coercion}

Incentives can be structured as either rewards (e.g., cash, reductions in insurance contributions, or in-kind goods) or penalties (e.g., insurance surcharges). On one account, only threats can coerce since threats indicate that an individual's failure to behave in a desired manner will result in that individual being made worse off. ${ }^{52}$ Because penalties constitute threats, rewards appear ethically preferable. Still, a reward may also risk coercion insofar as the offer is one an individual could not reasonably refuse. ${ }^{53}$ Rewards very large in value may lead individuals to engage in behaviors that are not in their best interests. For example, patients receiving incentives for adherence may be less inclined to report side effects or other treatment-related difficulties such as an inability to work if they believe doing so may result in reduced or revoked incentives.

Policy makers should take seriously these treatment-related difficulties. Rather than remain unidirectional, ${ }^{54}$ mHealth interventions should connect health workers with individuals requiring extra attention by employing 2-way SMS communication or video conferencing to allow patients to provide reasons for non-adherence and still receive the incentive. Such feedback and patient assurance may enable ethical use of incentives within both DS-TB and DR-TB populations, despite the more severe side effects of DRTB treatment. In general, allowing interaction between patient and provider may facilitate development of caring relationships that support adherence, a potential benefit of DOT that may be lost with mHealth approaches.

\section{Incentive Size}

Reward incentives of small value may sufficiently spur adherence in high-income countries where patient factors such as present-biased preferences are the primary obstacles to adherence (as in the case of warfarin). However, social context and structural and health care service factors may be more significant in LMICs. For example, incentives of small value may be inadequate where patients experience significant income loss during treatment or must travel long distances for drug resupply. mHealth interventions for adherence

\section{Incentives structured as rewards generally are ethically preferable over those structured as penalties.}




\section{Individual adherence data can be used to better understand population-level adherence.}

\section{"Lotteries" in which patients have a chance of winning a reward, not a guarantee, are less likely to be coercive.}

should therefore consider using incentives of large value to enhance adherence by addressing major costs of treatment, which can include direct medical and non-medical costs and lost income. It is far from straightforward to determine noncoercive incentive values, which requires considerations of effectiveness and fairness alongside country-specific circumstances. Still, there are useful benchmarks, such as average basic household expenses or daily local labor rates. ${ }^{55}$

\section{Incentive Type}

Incentives can be provided with either more or less certainty, which has implications for effectively influencing motivation. Most incentives are fixed expectations whereby a reward of known value is provided whenever the qualifying activity is completed. However, incentives can be offered in less direct ways, for example, through lotteries. Here, patients who properly adhere (e.g., by ingesting all prescribed treatment doses within a specified period) receive a chance of winning a reward, not a guarantee. Lotteries are attractive because they can decouple behavior from the firm expectation of receiving immediate benefits for adherence, while still functioning as an effective "nudge." ${ }^{56}$ Such incentives are less likely to coerce patients. Furthermore, lack of a certain reward may help avoid "crowding-out" intrinsic motivation, ${ }^{56}$ which is concerning for several reasons ${ }^{57}$ and has been observed empirically in some cases, ${ }^{58}$ although not universally. ${ }^{59,60}$

\section{Incentive Frequency}

Incentive frequency may impact patients' susceptibility to present-biased preferences. For example, when considering the short-term benefit of no side effects, patients may de-prioritize the relatively long-term benefit of a small monthly or yearly reward just as they would the long-term benefit of cure. Daily incentives can counter this tendency. ${ }^{50}$ Lotteries can be especially useful. For example, participants in a warfarin adherence study were given a daily 1 -in-5 chance of winning US\$10 and a 1-in-100 chance of winning US\$100, with an expected value of US\$3 per day. In addition to providing feedback to patients with successful adherence, participants were also told what they would have won had they adhered, exploiting the motivating power of anticipated regretanother powerful behavioral economics principle. $^{22}$ Providing incentives on a less frequent basis (e.g., weekly) can still have an impact, but higher frequency can increase the traction of the approach.

\section{Balance of Individual and Public Good}

Individual adherence data can be used to better understand population-level adherence. Knowing in advance which regions have lower adherence rates can enable more efficient resource allocation such as drug restocking-insofar as there are no prohibitive supply chain or logistical obstaclestherefore reducing the risk that patients nonadhere from lack of drugs. Officials could also study these regions to develop detailed knowledge of the factors working against adherence within specific contexts. Conversely, analyzing regions with high adherence rates could reveal best practices for application elsewhere. Striving to keep individual-level adherence data anonymous, or implementing robust firewalls where this is not feasible, can help ensure that each approach serves the public good while respecting individual privacy.

DE that employs wearable monitoring technologies equipped with location surveillance, while potentially stigmatizing and intrusive, could alternatively assist in contact tracing and interrupting disease transmission. Policy around the use of mHealth must consider and balance the potential for promoting both individual and public good.

\section{THE ETHICAL BOTTOM LINE}

In summary, mHealth interventions for TB treatment adherence have the potential to ethically improve on DOT in line with WHO's End TB Strategy. In Table 2, we summarize the strengths and weaknesses of each intervention category, highlight areas of ethical concern and opportunities for ethical improvement over DOT, and provide a set of recommendations for future interventions.

Based on this analysis, we suggest urinalysisbased DM as the mHealth intervention category with the greatest potential for ethical acceptability. Assuming optimal technical functioning, DM maximizes accuracy in monitoring by most effectively restricting opportunities for deception. This model also minimizes stigmatization and intrusiveness compared with DOT and other monitoring technologies, preserving patient agency and promoting autonomy.

Of course, mHealth for TB treatment adherence will be implemented in diverse health care contexts and adherence barriers will vary widely. Urinalysis-based DM may not always be the most 
practical or cost-effective intervention. Where other intervention categories are more appropriate, our summary and recommendations also provide valuable ethical guidance. The ethical strengths and weaknesses of each mHealth intervention category must always be balanced with the specific barriers faced by patients, as well as the practical realities of implementing public health programs such as cost-effectiveness. Difficult choices regarding trade-offs are inevitable, but ethical acceptability should be a critical component of these debates.

\section{CONCLUSION}

Controlling TB is urgent. While proper treatment adherence is critical to TB control, barriers to adherence are significant and diverse. mHealth constitutes an emerging field with particular promise to address such barriers, thus improving individual and population health and health systems efficiency. The ethical framework established here is intended to help with developing ethical mHealth interventions for TB adherence by flagging key ethical issues that need to be considered in planning, implementing, and evaluating programs.

Acknowledgments: We are grateful to Jeff Campbell and Jessica Haberer for helpful discussion and comments on an earlier version of the manuscript as well as the comments offered by our anonymous reviewers.

Competing Interests: None declared.

\section{REFERENCES}

1. Schmidt H, Gostin LO, Emanuel EJ. Public health, universal health coverage, and Sustainable Development Goals: can they coexist? Lancet. 2015;386(9996):928-930. CrossRef. Medline

2. Lewis $T$, Synowiec $C$, Lagomarsino $G$, Schweitzer J. E-health in low- and middle-income countries: findings from the Center for Health Market Innovations. Bull World Health Organ. 2012; 90(5):332-340. CrossRef. Medline

3. World Health Organization (WHO). Digital health in the TB response: scaling up the TB response through information and communication technologies. Geneva: WHO; 2014. Available from: http://www.who.int/tb/publications/ehealth_TB.pdf

4. Denkinger CM, Grenier J, Stratis AK, Akkihal A, Pant-Pai N, Pai M. Mobile health to improve tuberculosis care and control: a call worth making. Int J Tuberc Lung Dis. 2013;17(6):719-727. CrossRef. Medline

5. van Gemert-Pinjen JEWC, Wynchank S, Covvey HD, Ossebaard HC. Improving the credibility of electronic health technologies. Bull World Health Organ. 2012;90(5):323-323A. CrossRef. Medline

6. World Health Organization (WHO); International Telecommunication Union. National eHealth strategy toolkit. Geneva: WHO; 2012. Co-published by International
Telecommunication Union. Available from: https://www.itu.int/ dms_pub/itu-d/opb/str/D-STR-E_HEALTH.05-2012-PDF-E.pdf

7. Kay M, Santos J, Takane M. mHealth: new horizons for health through mobile technologies. Geneva: World Health Organization; 2011. Available from: http://www.who.int/goe/ publications/goe_mhealth_web.pdf

8. World Health Organization (WHO). Global tuberculosis report 2015. Geneva: WHO; 2015. Available from: http://apps.who. int/iris/bitstream/10665/191102/1/9789241565059_eng.pdf

9. World Health Organization (WHO) [Internet]. Geneva: WHO; c2016. Tuberculosis: fact sheet no. 104; reviewed $2016 \mathrm{Mar}$ [cited 2015 Dec 18]. Available from: http://www.who.int/ mediacentre/factsheets/fs104/en/

10. World Health Organization (WHO). Treatment of tuberculosis: guidelines, 4th ed. Geneva: WHO; 2010. Available from: http://apps.who.int/iris/bitstream/10665/44165/1/ 9789241547833_eng.pdf

11. Centers for Disease Control and Prevention (CDC) [Internet]. Atlanta (GA): CDC. Drug-resistant TB; last updated 2016 Apr 13 [cited 2015 Dec 18]. Available from: http://www.cdc.gov/tb/ topic/drtb/default.htm

12. World Health Organization (WHO). Global strategy and targets for tuberculosis prevention, care and control after 2015: report by the Secretariat. Geneva: WHO; 2013. Available from: http:// apps.who.int/gb/ebwha/pdf_files/EB134/B134_12-en.pdf

13. Islam MA, May MA, Ahmed F, Cash RA. Making tuberculosis history: community-based solutions for millions. Dhaka (Bangladesh): University Press; 2011.

14. Munro SA, Lewin SA, Smith HJ, Engel ME, Fretheim A, Volmink J. Patient adherence to tuberculosis treatment: a systematic review of qualitative research. PLoS Med. 2007;4(7):e238. CrossRef. Medline

15. Tanimura T, Jaramillo $E$, Weil D, Raviglione $M$, Lönnroth $K$. Financial burden for tuberculosis patients in low- and middleincome countries: a systematic review. Eur Respir J. 2014; 43(6): 1763-1775. CrossRef. Medline

16. Johansson E, Long NH, Diwan VK, Winkvist A. Gender and tuberculosis control: perspectives on health seeking behaviour among men and women in Vietnam. Health Policy. 2000; 52(1):33-51. CrossRef. Medline

17. Centers for Disease Control and Prevention (CDC) [Internet]. Atlanta (GA): $C D C$. Latent tuberculosis infection: a guide for primary health care providers; last updated $2013 \mathrm{Apr} 3$ [cited 2015 Dec 18]. Available from: http://www.cdc.gov/tb/ publications/thbi/treatment.htm

18. Törün T, Güngör $G$, Ozmen I, Bölükbaşi Y, Maden E, Biçakçi B, et al. Side effects associated with the treatment of multidrugresistant tuberculosis. Int J Tuberc Lung Dis. 2005; 9(12):1373-1377. Medline

19. Datiko DG, Lindtiørn B. Cost and cost-effectiveness of treating smear-positive tuberculosis by health extension workers in Ethiopia: an ancillary cost-effectiveness analysis of community randomized trial. PLoS One. 2010;5(2):e9158. CrossRef. Medline

20. World Bank Open Data [Internet]. Washington (DC): The World Bank; c2016. Mobile cellular subscriptions (per 100 people); [cited 2015 Jun 10]. Available from: http://data.worldbank. org/indicator/IT.CEL.SETS.P2

21. Barclay E. Text messages could hasten tuberculosis drug compliance. Lancet. 2009;373(9657):15-16. CrossRef. Medline

22. Volpp KG, Loewenstein G, Troxel AB, Doshi J, Price M, Laskin M, et al. A test of financial incentives to improve warfarin adherence. BMC Health Serv Res. 2008;8(1):272. CrossRef. Medline 
23. Center for Health Market Innovations (CHMI) [Internet]. Washington (DC): CHMl; c2016. TIBU: Year launched: 2012; [cited 2015 Dec 18]. Available from: http:// healthmarketinnovations.org/program/tibu

24. Boccia D, Hargreaves J, Lönnroth K, Jaramillo E, Weiss J, Uplekar $\mathrm{M}$, et al. Cash transfer and microfinance interventions for tuberculosis control: review of the impact evidence and policy implications. Int J Tuberc Lung Dis. 2011;15 Suppl 2:S34-S49. CrossRef. Medline

25. Liu X, Lewis JJ, Zhang H, Lu W, Zhang S, Zheng G, et al. Effectiveness of electronic reminders to improve medication adherence in tuberculosis patients: a cluster-randomised trial. PLoS Med. 2015;12(9):e1001876. CrossRef. Medline

26. Garfein RS. mHealth for monitoring tuberculosis treatment adherence [webinar]. New Brunswick (NJ): Rutgers Global Tuberculosis Institute; 2014.

27. World Health Organization (WHO) [Internet]. Geneva: WHO; c2016. The 5 elements of DOTS: element 3: standardized treatment, with supervision and patient support; [cited 2015 Dec 19]. Available from: http://www.who.int/tb/dots/ whatisdots/en/index $2 . \mathrm{html}$

28. Garfein RS, Collins K, Muñoz F, Moser K, Cerecer-Callu P, Raab $\mathrm{F}$, et al. Feasibility of tuberculosis treatment monitoring by video directly observed therapy: a binational pilot study. Int J Tuberc Lung Dis. 2015;19(9):1057-1064. CrossRef. Medline

29. Hanina A. Automated DOT: facial recognition soffware to confirm medication adherence on mobile devices. New York: AiCure; 2014. Available from: http://www.tbcontrollers.org/ docs/posters-2014-national-tb-conference/Hanina_AutomatedDOT-Facial-Recognition-Software_June2014NTC.pdf

30. 99Dots [Internet]. Microsoft Research; [cited 2015 Dec 19] Available from: http://99dots.org

31. WestRock [Internet]. Sion (Switzerland): WestRock Switzerland Ltd.; c2016. MEMSCap medication event monitoring system; [cited 2015 Dec 19]. Available from: http://www.mwvaardex. com/index.php/our-adherence-solutions-data-collection/ memscap-tm

32. GlowCap [Internet]. Los Angeles (CA): Vitality, Inc.; c2013. Product; [cited 2015 Dec 19]. Available from: http://www. glowcaps.com/product/

33. WisePill [Internet]. WisePill Technologies; [cited 2015 Dec 19]. Available from: http://www.wisepill.com/

34. eTect [Internet]. Newberry (FL): eTect, Inc.; c2014. What we do; [cited 2015 Dec 19]. Available from: http://etectbio.com

35. Hafezi H, Robertson TL, Moon GD, Au-Yeung KY, Zdeblick MJ, Savage GM. An ingestible sensor for measuring medication adherence. IEEE Trans Biomed Eng. 2015;62(1):99-109. CrossRef. Medline

36. Gomez-Marquez J. Adhere.IO. In: Donner J, Mechael P, editors mHealth in practice: mobile technology for health promotion in the developing world. New York: Bloomsbury Academic; 2013. p. 162-172.

37. Schmidt $H$. Bonuses as incentives and rewards for health responsibility: a good thing? J Med Philos. 2008;33(3):198-220 CrossRef. Medline

38. Centers for Disease Control and Prevention (CDC) [Internet] Atlanta (GA): CDC. Self-study modules on tuberculosis. Module 9: patient adherence to tuberculosis treatment: using incentives and enablers to improve adherence; last updated 1999 Oct [cited 2016 Jun 2]. Available from: http://www.cdc.gov/tb/ education/ssmodules/pdfs/9.pdf

39. Moulding T. A neglected research approach to prevent acquired drug resistance when treating new tuberculosis patients. Int J Tuberc Lung Dis. 2011;15(7):855-861. CrossRef. Medline

40. Greaves F, Ouyang H, Pefole M, MacCarthy S, Cash RA. Compliance with DOTS diagnosis and treatment recommendations by private practitioners in Kerala, India. Int J Tuberc Lung Dis. 2007;11(1):110-112. Medline

41. DeMaio J, Schwartz L, Cooley P, Tice A. The application of telemedicine technology to a directly observed therapy program for tuberculosis: a pilot project. Clin Infect Dis. 2001; 33(12):2082-2084. CrossRef. Medline

42. Courtwright $A$, Turner $A N$. Tuberculosis and stigmatization: pathways and interventions. Public Health Rep. 2010; 125 Suppl 4:34-42. Medline

43. Noyes J, Popay J. Directly observed therapy and tuberculosis: how can a systematic review of qualitative research contribute to improving services? A qualitative meta-synthesis. J Adv Nurs. 2007;57(3):227-243. CrossRef. Medline

44. Corrigan PW, Watson AC. Understanding the impact of stigma on people with mental illness. World Psychiatry. 2002;1(1): 16-20. Medline

45. Sharp RR. Ingestible drug adherence monitors: trending toward a surveillance society? Am J Bioeth. 2015;15(11):1-2. CrossRef. Medline

46. Hensel BK, Demiris G, Courtney KL. Defining obtrusiveness in home telehealth technologies: a conceptual framework. J Am Med Inform Assoc. 2006;13(4):428-431. CrossRef. Medline

47. Weiler-Ravell D, Leventhal A, Coker RJ, Chemtob D. Compulsory detention of recalcitrant tuberculosis patients in the context of a new tuberculosis control programme in Israel. Public Health. 2004; 118(5):323-328. CrossRef. Medline

48. Bock NN, Sales RM, Rogers T, DeVoe B. A spoonful of sugar...: improving adherence to tuberculosis treatment using financial incentives. Int J Tuberc Lung Dis. 2001;5(1):96-98. Medline

49. O'Donoghue T, Rabin M. Doing it now or later. Am Econ Rev. 1999;89(1):103-124. CrossRef

50. Asch DA, Muller RW, Volpp KG. Automated hovering in health care-watching over the 5000 hours. N Engl J Med. 2012; 367(1):1-3. CrossRef. Medline

51. Lutge EE, Wiysonge CS, Knight SE, Sinclair D, Volmink J. Incentives and enablers to improve adherence in tuberculosis. Cochrane Database Syst Rev. 2015;(9):CD007952. CrossRef. Medline

52. Wertheimer A. Coercion. Princeton (NJ): Princeton University Press; 1988.

53. O'Neill $O$. Which are the offers you can't refuse? In: Frey RG, Morris CW, editors. Violence, terrorism, and justice. Cambridge: Cambridge University Press; 1991. p. 70-95.

54. van Heerden A, Tomlinson M, Swartz L. Point of care in your pocket: a research agenda for the field of $m$-health. Bull World Health Organ. 2012;90(5):393-394. CrossRef. Medline

55. International Committee of the Red Cross (ICRC); International Federation of Red Cross and Red Crescent Societies. Guidelines for cash transfer programming. Geneva: ICRC; 2007. Co-published by International Federation of Red Cross and Red Crescent Societies. Available from: http://www.ifrc.org/Global/ Publications/disasters/guidelines/guidelines-cash-en.pdf

56. Schmidt H. Planning, implementing and evaluating the effectiveness and ethics of health incentives: key considerations. Eurohealth. 2014;20(2):10-14. Available from: http://www. euro.who.int/_data/assets/pdf_file/0017/252251/ EuroHealth_v20n2.pdf 
57. Gorin M, Schmidt H. 'I did it for the money': incentives, rationalizations and health. Public Health Ethics. 2015;8(1): 34-41. CrossRef

58. Frey BS, Jegen R. Motivation crowding theory. J Econ Surv. 2001;15(5):589-611. CrossRef

59. Promberger $M$, Marteau TM. When do financial incentives reduce intrinsic motivation? Comparing behaviors studied in psychological and economic literatures. Health Psychol. 2013; 32(9):950-957. CrossRef. Medline
60. Sen AP, Huffman D, Loewenstein G, Asch DA, Kullgren JT, Volpp KG. Do financial incentives reduce intrinsic motivation for weight loss? Evidence from two tests of crowding out. Presented at: 5th Biennial Conference of the American Society of Health Economics (ASHEcon 2014); 2014 Jun 23-25; Los Angeles, California. Paper available from: http://nebula.wsimg.com/ 48d17bblab7e18ec9dc988823fb69eal? AccessKeyld=6D9673982F271B3E540E\&disposition= 0\&alloworigin $=1$

\section{Peer Reviewed}

Received: 2016 Jan 27; Accepted: 2016 Apr 14

Cite this article as: DiStefano MJ, Schmidt $\mathrm{H}$. mHealth for tuberculosis treatment adherence: a framework to guide ethical planning, implementation, and evaluation. Glob Health Sci Pract. 2016;4(2):21 1-221. http://dx.doi.org/10.9745/GHSP-D-16-00018

(c) DiStefano and Schmidt. This is an open-access article distributed under the terms of the Creative Commons Attribution License, which permits unrestricted use, distribution, and reproduction in any medium, provided the original author and source are properly cited. To view a copy of the license, visit http://creativecommons.org/licenses/by/3.0/. When linking to this article, please use the following permanent link: http://dx.doi. org/10.9745/GHSP-D-16-00018 